\title{
The perceived burden of care among caregivers of survivors of cerebrovascular accident following discharge from a private rehabilitation unit
}

\author{
Lyndall Serfontein, B OT (UFS), M OT (UFS) https://orcid.org/0000-000 I-6524-I I $7 X$ \\ Occupational therapist, Life Pasteur Rehabilitation Hospital, Bloemfontein
}

\author{
Marieta Visser, B OT (UFS), MSc OT (Wits) https://orcid.org/0000-0002-8825-4683 \\ Lecturer, Department of Occupational Therapy, Faculty of Health Sciences, University of the Free State, Bloemfontein, South \\ Africa
}

Mia van Schalkwyk, B OT (UFS), M OT (UFS) https://orcid.org/0000-0003-3966-43 I

Affiliated lecturer. Department of Occupational Therapy, Faculty of Health Sciences, University of the Free State, Bloemfontein, South Africa

\author{
Cornel van Rooyen, B Comm (UFS), M Comm (UFS) https://orcid.org/0000-0002-5092-2957 \\ Lecturer, Department of Biostatistics, Faculty of Health Sciences, University of the Free State, Bloemfontein, South Africa
}

Introduction: The transition between inpatient rehabilitation and discharge of survivors of stroke from private rehabilitation services in South Africa is often challenging. After the stroke survivor is discharged, caregivers have an important role as an extension of rehabilitation, although the occupation of caregiving is often unplanned. This study investigated the factors associated with the burden of care experienced by patients' caregivers.

Methods: A quantitative descriptive study was conducted with 63 patients and 63 caregivers, using a consecutive, non-randomised sampling method. Patients' Functional Independence Measure (FIM) scores upon discharge were obtained. Telephonic interviews were conducted with the caregivers two months after the patients' discharge, using the Modified Caregiver Strain Index (MCSI) and a demographic data questionnaire to obtain their perceived burden of care.

Results: Patients' median FIM score at discharge was 86, indicating that they needed minimal assistance. After discharge, caregivers experienced minimal to moderate strain (burden of care) according to the MCSI score. The associated factors that were identified included financial, physical, psychological and social aspects, of which financial strain was encountered most regularly. Caregivers also seemed to have unbalanced occupational profiles.

Conclusions: Better caregiver training and support should be provided by private rehabilitation services for better integration of stroke survivors into the community.

Key words: Cerebrovascular accident; stroke; caregivers; burden of care; private inpatient rehabilitation

\section{INTRODUCTION}

Survivors of a cerebrovascular accident (CVA) often experience permanent impairment and need assistance with their activities of daily living ${ }^{1-3}$, as a full recovery only occurs in only approximately $45 \%$ of patients with CVA 4 . Comprehensive early intervention by an inter-professional team can assist patients to reach their maximum potential by decreasing the effect of disability. Rehabilitation thus plays a vital role in the transition between medical management and patients' return to independent participation in daily activities, community integration and their return to meaningful and productive work activities ${ }^{5,6}$.

Rehabilitation services provided in the private sector in South Africa are primarily funded by medical schemes applying regulations that limit the time spent in rehabilitation ${ }^{7}$. Nevertheless, inpatient rehabilitation aims to optimise patients' outcomes ${ }^{8,9}$, benefiting both the patients and funders by preventing complications such as falls, contractures, shoulder pain/subluxation and pressure sores.

The goal of rehabilitation is generally to achieve function at the highest level of independence possible for each individual before discharge ${ }^{10}$. Following the inpatient rehabilitation process, most patients should be independent or may need only minimal assistance with activities of daily living '". Furthermore, inpatient rehabilitation may provide a safe environment for patients to help them make sense of what has happened to them and grant them access to the necessary tools to start rebuilding their lives after discharge ${ }^{8}$. However, the primary focus of inpatient rehabilitation is usually the patient's return to home ${ }^{12}$. Continued support in terms of outpatient rehabilitation is often required additionally. Further rehabilitation outcomes such as community reintegration (for example, making use of public transport and social interaction), as well as productive activity (returning to work, adaptations at work), all need to be addressed during outpatient therapy ${ }^{12}$, but are not always achieved.

At the specific rehabilitation unit where this study was conducted, patients engage in various types of therapy on a daily basis, offered by an inter-professional team. Family meetings are also scheduled with each patient and his/her family to report on the patient's diagnosis, prognosis, therapy goals and progress, and to plan the patient's discharge, which includes assessment of home accessibility and the need for assistive devices. Caregiver training is usually offered and home programmes are provided, while outpatient therapy is recommended where needed ${ }^{\prime 3}$. However, the transition between inpatient rehabilitation and discharge of stroke patients from private rehabilitation services in South Africa (similar to the research setting), in general presents salient challenges. One 
of these challenges relates to the possible permanent impairment of stroke survivors, creating a need for continuous support that can place a high responsibility and burden of care on their caregivers ${ }^{11,14}$.

From an occupational therapy perspective, caregiving has been described as an everyday occupation ${ }^{15}$, a co-occupation ${ }^{16-20}$ and also a collective occupation ${ }^{21}$. It involves aspects of shared physicality, emotionality and intentionality, embedded in shared meaning, where the caregiver and patient interact and both are affected by each other's activity performance ${ }^{17}$.

Some caregivers might value this new role as positive and derive pleasure and meaning from $\mathrm{it}^{22}$. Yet individual caregivers' circumstances differ greatly, and other caregivers could feel unprepared for their new role upon the patient's discharge from rehabilitation, and might experience burden of care ${ }^{12}$. Caregivers who assist patients after discharge are often family members with no previous experience or training ${ }^{23}$. An increased demand in terms of finances, time and other caregiver-related activities is placed on family members and/or caregivers, who often are forced by circumstances to take up the unanticipated role as caregiver for the patient with CVA ${ }^{24}$. Not only is it expected of caregivers to assist patients with daily living activities, maintaining and improving skills learnt in rehabilitation in order to improve the patient's quality of life, also becomes part of the caregiver's role ${ }^{23}$. They therefore play an important role by becoming an extension of rehabilitation delivery post-discharge ${ }^{25}$.

Previous research has shown that caregivers might stop participating in activities that previously had been meaningful to them, and therefore experience occupational loss after taking up their roles as caregivers ${ }^{26}$. Their caregiving-related duties are very time-consuming, and a general perception that the patient's needs should be placed before their own, often leads to neglect of their own occupational needs ${ }^{27}$. Aspects that negatively affect caregivers' occupational balance are influenced by the daily roles they need to fulfil, their own physical and psychological well-being, the availability of sufficient support systems, and their future goals ${ }^{27}$. Therefore, they can face physical, psychological, emotional, social and financial challenges ${ }^{28}$. Consequences of being a caregiver include higher stress levels, higher burden of care, lower energy levels, decreased psychological well-being ${ }^{26}$ and also tiredness, anxiety, despair, frustration and isolation ${ }^{29}$.

Early identification and involvement of a caregiver in the inpatient rehabilitation process may enhance a patient's recovery towards functional outcomes. Caregiver training, which informs caregivers of the resources available and includes advice on stress management, may lead to a reduced burden of care ${ }^{30}$. Family meetings, caregiver training and complete discharge reports (including available resources post-discharge) all form part of the rehabilitation process at the inpatient rehabilitation unit where this study was conducted ${ }^{13}$

At the time of the study, a limited number of South Africanspecific studies was available regarding the burden of care experienced by caregivers post-discharge (on a national and provincial level), especially from private inpatient rehabilitation settings.

The aim of this study was to investigate the perceived burden of care experienced by caregivers of patients with CVA with functional impairments, after discharge from a private rehabilitation unit in Bloemfontein, South Africa.

\section{METHODS}

\section{Study design and research context}

A quantitative, descriptive study was conducted at a private inpatient rehabilitation unit in Bloemfontein. The unit has a comprehensive rehabilitation team, and patients and their families are viewed as part of the team and are included in goal-setting and future planning for the patients. Patients with CVA's duration of stay in the rehabilitation unit depends on the authorisation granted by their medical schemes, progress observed in the patient and readiness for discharge $\mathrm{e}^{7,13}$. After discharge, some medical schemes also provide benefits such as caregiver support, home visits by rehabilitation professionals and outpatient therapy ${ }^{3 !}$.

\section{Population and sampling}

A consecutive, non-randomised sampling method ${ }^{32}$ was used in selecting participants - patients with CVA and their primary caregivers - from the rehabilitation unit. Inclusion was regulated based on the following criteria:

I. patients with ischemic/haemorrhagic CVAs and/or acute/previous CVAs including co-morbidities, from all functional levels;

2. patients who were discharged to a home environment and living with a family member or caregiver.

3. caregivers who were older than I8 years, identified as the patient's primary caregiver, and who had been taking care of the patient for at least one month after discharge, were included if they stayed with the patient for at least four hours during day time, had access to a phone, and could understand Afrikaans, English or Sesotho. Caregivers were included regardless of caregiver training or payment received.

A total of 68 caregivers of patients with CVA consented to participate, of which a final number of 63 met the inclusion criteria for the study. Patients and their caregivers were excluded if patients were discharged from the rehabilitation unit to another facility, lived alone, or if caregivers did not give informed consent to participate in the study. If caregivers did not answer their phones after five attempts to contact them, they were also excluded.

\section{Measuring instruments}

The following three measurement tools were used to gather the data:

* a background information document to obtain information from patients' hospital files, including Functional Independence Measure (FIM) ${ }^{33}$ scores upon discharge;

* a demographic data questionnaire compiled by the first author and used in the telephonic interviews with the caregivers two months post-discharge; and

* the Modified Caregiver Strain Index (MCSI) ${ }^{34}$ also used in the telephonic interviews with the caregivers two months postdischarge.

The FIM aims to assess patients' levels of independence with activities of daily living ${ }^{35}$ and serves as an official tool for assessing patients' level of incapacity, indicating the level of assistance required to perform their daily activities. The instrument was specifically developed for patients with lower levels of functioning admitted to inpatient rehabilitation units ${ }^{33}$. It uses a seven-point scale and consists of 18 items ( 13 items to assess motor abilities and five items to assess cognitive abilities). Each of these items is awarded a score between one (the patient needs total assistance) and seven (total independence), thus the maximum score that can be obtained is $126^{36}$. At the rehabilitation unit where this study was conducted, therapists record FIM scores on a weekly basis. These scores are reported to relevant medical schemes as part of the patients' weekly progress reports. For the purpose of this study, patients' FIM scores, as allocated by trained therapy staff upon discharge, were used to determine the patients' level of functional independence at the time of discharge.

The demographic data questionnaire was designed by the first author to obtain demographic information, as well as additional information regarding caregivers' burden of care from the caregiver to determine which other factors, such as roles and occupations, might contribute to the caregivers' perceived burden of care. The questions in the demographic data questionnaire were formulated in line with the research objectives and were based on available literature. It consisted of five categories as follows: (i) demographic information ${ }^{22,28,37}$; (ii) caregivers' occupations, performance patterns and well-being ${ }^{22,25-27,38}$, (iii) caregivers' performance skills ${ }^{29,39}$, (iv) caregivers' view of patients' client factors $\mathrm{s}^{28,37,40-45}$, and $(\mathrm{v})$ environmental factors $\mathrm{s}^{27,28,46}$. 
The MCSI was developed as an improved version of the Caregiver Strain Index (CSI) which was initially designed to measure stress as perceived by informal caregivers ${ }^{47}$, which could contribute to their burden of care. It has been used with success in a number of studies regarding the burden of care of CVA patients, and has proved to also be of cultural relevance within the South African context ${ }^{48,49}$. The MCSI is appropriate for use as a screening tool to identify caregivers' perceived burden of care/strain. It focusses on matters pertaining to financial, physical, psychological, social and personal factors, and at least one question is available for each of these aspects. The MCSI consists of 13 questions with examples, where caregivers can answer "yes, on a regular basis" (score two points); "yes, sometimes" (score one point); or "no" (score zero) ${ }^{34}$. The maximum score that caregivers can obtain with the MCSI is 26. Therapists must use clinical reasoning in deciding when to investigate caregivers' burden of care further, as the MCSI merely serves as a screening tool ${ }^{34}$. Therefore, for the purpose of this study, the authors used the interpretation guide of the $\mathrm{CSI}^{47}$ to inform the interpretation of the MCSI results, and proposed that a score of 14 or higher (out of 26) was an indicator of high burden of care.

\section{Data collection}

Data collection occurred in two stages. Prior to or on the day of discharge from the rehabilitation unit, all patients with CVA and their caregivers were approached and informed of the study, and invited to participate. The first author then established contact with the patient and primary caregiver on the day of discharge from the rehabilitation unit, during which written consent was obtained from both the patient and caregiver. The first author also recorded information from the patient's hospital file including the Functional Independence Measure (FIM) scores of the patient as evaluated by the team upon discharge. The background information questionnaire was then completed in order to establish which patients and their caregivers could be included in the study.

The second stage of the data collection process occurred two months after discharge, with the telephonic interviews with the caregivers who met the inclusion criteria. During these interviews, both a demographic data questionnaire and a standardised questionnaire, the Modified Caregiver Strain Index (MCSI), were administered.

A pilot study was conducted with two caregivers of previously discharged patients (with consent of both parties), in order to test the feasibility of the two telephonic questionnaires that included the standardised Modified Caregiver Strain Index (MCSI) and the non-standardised questionnaire.

The study was conducted over a period of nine months, which included a two month waiting period after the first patients were discharged and before the telephonic follow-ups were conducted. An average of seven to eight patients with CVA were admitted to the unit per month ${ }^{50}$ at the time of the study.

The demographic questionnaire used during the telephonic interview was available in Afrikaans, English and Sesotho. Forwardbackward translation was used to translate the questionnaire. The MCSI could not be translated, as it was standardised in English. A trained research assistant conducted the telephonic interview in Sesotho (in the presence of the first author) for caregivers who preferred to participate in Sesotho. A Sesotho script, from which the information and questions were read, was provided to the assistant.

All information recorded on the background questionnaire, the MCSI, and the demographic data questionnaire was coded and entered into an Excel spreadsheet for data analysis.

\section{Reliability and validity}

Interrater reliability was enhanced by the fact that the FIM scores were allocated only by staff members who had completed a licensed personnel examination using the Uniform Data System for Medical Rehabilitation's Online FIM Credentialing System ${ }^{33}$. This examination is taken on a two-yearly basis and is completed by all permanent staff members involved with patient rehabilitation.
The internal validity for the MCSI is higher than that of the CSI, with a test-retest reliability coefficient of $0.93^{33}$. A third of the study sample in other studies indicated a test-retest reliability coefficient of 0.88 after two weeks. Internal consistency was also high and no floor-ceiling effect was found ${ }^{51}$.

The first author made an effort to minimise measurement errors, such as non-responder bias, by attempting to contact each participant five times. If the time of the call was inconvenient, a more suitable appointment was made. Inter-rater reliability between the first author and research assistant was ensured by strictly reading the question on the questionnaire in a standard format. The interviews were not recorded, since the phone did not have an audio recording function. Written documentation was used to capture the exact answer provided by the participant. A pilot study was conducted on two caregivers to determine the practical feasibility of the questionnaires used during the telephonic interviews, although these results were not included in the final data analysis. The telephone was used in a quiet environment to minimise distractions.

\section{Ethical aspects}

Approval for this study was obtained from the Health Science Research Ethics Committee of the University of the Free State (reference HSREC 78/2016). Written permission was granted by the practice manager of the private rehabilitation unit where the study was conducted. Written informed consent was obtained from the patients (or next of kin if they were not able to give consent) and the caregivers. All information was kept strictly confidential and stored in a safe, secure environment. Numbers were used instead of names to ensure anonymity.

\section{Data analysis}

The data were analysed by the Department of Biostatistics, University of the Free State. Categorical data were summarised using frequencies and percentages. The numerical variables, FIM- and MCSI scores were summarised by ranges and medians. The median differences between groups were evaluated by means of the Kruskal-Wallis test ${ }^{52}$.

\section{RESULTS}

\section{Demographic information of caregivers and patients}

Demographic information of the patients included in the study, as well as their caregivers, is reflected in Table I below. The patients' median age was 58 years (range 18-82 years), while the caregivers had a median age of 52 years (range 23-76 years). The patients and caregivers were mostly female.

Table I: Patients' and caregivers' gender and median age

\begin{tabular}{|l|c|c|}
\hline \multirow{2}{*}{ Variable } & Patients $(\mathbf{n = 6 3 )}$ & Caregivers $(\mathbf{n = 6 3 )}$ \\
\cline { 2 - 3 } & $\mathbf{n}(\%)$ & $\mathbf{n}(\%)$ \\
\hline Gender & $28(44.4)$ & $13(20.6)$ \\
\hline Male & $35(55.6)$ & $50(79.4)$ \\
\hline Female & 58 years $(18-82)$ & 52 years $(23-76)$ \\
\hline Median age (range) &
\end{tabular}

Of the study sample of 63 caregivers, $32(50.8 \%)$ were spouses and I $8(28.6 \%)$ were children of CVA survivors. All caregivers were related to the patients. With the exception of one participant, all the caregivers lived with the person they cared for. Forty-five (7I.4\%) caregivers reported that they had between one and three other persons assisting them with taking care of the patients, e.g. family members, although these individuals were not necessarily related to the patients e.g. a domestic worker or informal caregiver. The remaining $18(28.6 \%)$ caregivers reported no additional caregiver assistance. 
Table II: Functioning Independence Measure (FIM) rating levels and the expected hours of care needed (Uniform Data System for Medical Rehabilitation $2012^{33}$ )*

\begin{tabular}{|c|c|c|c|c|}
\hline \multirow{2}{*}{ FIM level } & Total FIM score & $\begin{array}{c}\text { Estimated hours of caregiving } \\
\text { needed per day }\end{array}$ & Amount of assistance needed & Number of patients (n=63) \\
\cline { 3 - 5 } & $18-35$ & $6-8+$ & Total assistance & $\mathbf{n}(\%)$ \\
\hline 1 & $36-53$ & $5-7$ & Maximal assistance & $4(6.3)$ \\
\hline 3 & $54-71$ & $3-5$ & Moderate assistance & $7(4.8)$ \\
\hline 4 & $72-89$ & $2-3$ & Minimal assistance & $7(11.1)$ \\
\hline 5 & $90-107$ & $<1-2$ & Supervision/setup & $20(31.7)$ \\
\hline 6 & $108-125$ & 0 & Modified independence & $15(23.8)$ \\
\hline 7 & 126 & 0 & Complete independence & $14(22.2)$ \\
\hline
\end{tabular}

*Table adapted by L. Serfontein.

The majority of patients $(n=54 ; 85.7 \%)$ were admitted to the rehabilitation unit after their first CVA. Nine (14.3\%) had suffered a previous CVA. Patients had a variety of other medical conditions and their medical histories differed greatly. Commonly occurring additional medical conditions included hypertension $(n=44 ; 69.8 \%)$ and diabetes mellitus (type I and II) ( $n=17 ; 27.0 \%)$. Sixteen (25.4\%) patients suffered from cardiovascular disease or had a history of cardiovascular conditions or interventions.

\section{Patients' functional level upon discharge}

Table II above indicates the expected hours of care that patients might need according to their total FIM scores. For example, patients who mostly scored level one for each FIM item obtained a total FIM score of I8-35. It was expected that these patients would need from six to more than eight hours of care on a daily basis, which is regarded as total assistance.

In this study, four patients (6.4\%) had a total FIM score of 18 35 (level I) and required total assistance of more than six hours of caregiving per day. Ten patients (I5.9\%) required between three and seven hours of caregiving per day (FIM levels 2 and 3). The majority of patients $(n=49 ; 77.8 \%)$ needed either minimal assistance or supervision, or were classed as modified independent (FIM levels $4-6$ ). These patients required up to three hours of caregiving per day.

\section{Therapy received}

Patients' duration of stay in the rehabilitation unit varied between less than one week and more than 12 weeks. This variation in length of stay can mainly be ascribed to the availability of funding, be it private or medical scheme funds. Fifteen $(23.8 \%)$ patients were admitted to the rehabilitation unit from less than one up to five weeks, $43(68.3 \%)$ between six and nine weeks, and five $(7.9 \%)$ for 10 weeks and longer. Most patients $(n=43 ; 68.3 \%)$ did not receive any outpatient therapy after discharge, or only continued with the home programme provided by the rehabilitation unit. The frequency of the outpatient therapy sessions varied between less than once a month to more than three times a week. Factors responsible for this variation include lack of access to outpatient therapy facilities and limited availability of these services. Most caregivers $(n=43 ; 68.3 \%)$ indicated that longer time in rehabilitation would not necessarily have relieved their burden of care.

\section{Home environment of patients}

Participants (caregivers and their patients) came from a wide variety of towns, rural areas and provinces in South Africa. Fiftyseven $(90.5 \%)$ had an indoor bathroom, of which 32 (56.1\%) had both a bath and a shower, although the study did not enquire about the adaptation of these facilities for their needs. Thirty-one $(50.8 \%)$ caregivers reported to have between one and eight steps in front of the house where they provided care. Most caregivers $(n=56 ; 88.9 \%)$ indicated that the house was adequately adapted for the patient's needs. Caregivers who did not feel that the house was adequately adapted, provided reasons such as stairs inside the house, outdoor bathroom, having too many residents in the house, or the rooms being too small. Many patients still used assistive devices at times, such as a wheelchair $(n=31 ; 49.2 \%)$ and/or a walking aid $(n=30 ; 47.6 \%)$. Some patients also made use of a commode $(n=2 ; 3.2 \%)$, bath board $(n=1 ; 1.6 \%)$, grab rail $(n=3 ; 4.8 \%)$, and/or transfer board $(n=3 ; 4.8 \%)$. Twentyfour $(38.1 \%)$ patients did not use any assistive devices, and 39 $(61.9 \%)$ caregivers felt that the assistive devices used by patients were sufficient for their needs.

\section{Patients' functional level two months post discharge}

At two months after discharge, caregivers were asked to provide information on activities of daily living for which patients still needed physical assistance or supervision. Activities mostly requiring physical assistance included bathing $(n=30 ; 47.6 \%)$, upper body dressing $(n=19 ; 30.2 \%)$, lower body dressing $(n=26 ; 41.3 \%)$ and climbing stairs $(n=28 ; 44.4 \%)$. Supervision was mostly needed for activities such as locomotion (mobilisation) $(n=18 ; 28.6 \%)$ and climbing stairs $(n=12 ; 19.0 \%)$. Furthermore, $52(82.5 \%)$ caregivers felt that the patients' abilities had improved since discharge or since they started caring for the patient, despite the fact that most patients did not receive outpatient therapy after discharge. At two months post-discharge, $16(25.4 \%)$ caregivers indicated that patients had acquired other illnesses or injuries after discharge, which varied, e.g. flu or back pain. Only one (6.3\%) patient fell after discharge according to the caregivers interviewed.

\section{Caregiving as occupation}

Most caregivers $(n=49 ; 77.8 \%)$ did not have any previous experience as a caregiver. Their level of education ranged from primary school level to postgraduate qualifications. Twenty-six (4I.3\%) caregivers completed school and $15(23.8 \%)$ obtained diplomas. Most caregivers $(n=52 ; 82.5 \%)$ attended caregiver training at the rehabilitation unit upon the patient's discharge. Four (6.3\%) caregivers previously worked as caregivers or nurses.

Of the study sample, $33(52.4 \%)$ caregivers were not employed or only had a part-time job, and $30(47.6 \%)$ caregivers had a fulltime job reporting their working hours to range between four and 12 hours per day. Caregivers who indicated they were working 12 hours a day $(n=5 ; 13.2 \%)$ and still taking care of patients for at least four hours during day time, explained that they were working night shifts or flexible hours, or from home. Responsibilities in addition to their work and caregiving-related duties were divided as follow: $36(57.1 \%)$ had to take care of children, $58(92.1 \%)$ participated in household tasks and $44(69.8 \%)$ participated in recreational tasks.

Caregivers were asked to indicate how many hours they spent on caregiving per day, and on other responsibilities such as child care, household tasks, recreation, or other activities. It has to be noted that estimations provided by the caregivers were subjective and the accuracy of their calculations was not verified. 
As per the inclusion criteria, all caregivers included in this study stayed with the patient (and thus assumed the role of a caregiver), for at least four hours during day time. Thirty five (55.6\%) of caregivers reported spending between two and four hours on actual caregiving tasks per day, and I $5(23.8 \%)$ caregivers indicated that they spent five to six hours on caregiving per day. (Fifty $(79.4 \%$ ) caregivers felt that they spent an adequate amount of time on caregiving-related duties (not too much or too little time). However, $45(71.4 \%)$ caregivers indicated that they had between one and three persons assisting them with their caregiving-related tasks, which might have influenced their answers.

Most caregivers $(n=51 ; 81.0 \%)$ indicated that they were healthy at the time of the interview. Seventeen $(27.0 \%)$ caregivers spent four hours a day taking care of children, 31 (49.2\%) spent four to five hours on household tasks, and $36(57.1 \%)$ spent two to four hours a day on recreational activities. Caregivers seemed to have unbalanced occupational profiles, as $33(52.4 \%)$ did not have a full-time job, I 5 (23.8\%) spent more than four hours a day on recreational activities and $24(38.1 \%)$ caregivers spent more than four hours a day on household tasks.

\section{Caregiver strain (burden of care) and associated factors}

In this study, the median score on the MCSI was nine, ranging between 2 and 22 . This wide range indicated that the burden of care experienced by caregivers differed greatly. As guidelines for the interpretation of the MCSI are limited, the authors agreed on the following guidelines for this study: a score of I 4 and higher was posited as an indication of a high burden of care, and a score of less than 14 as a minimal to moderate burden of care. Most caregivers $(n=51 ; 81.0 \%)$ experienced a minimal/moderate burden of care (a score of less than 14).

For the purpose of this study, the MCSI questions ${ }^{34}$ were categorised into financial, physical, psychological, social and personal aspects. Scores obtained for each aspect of the MCSI are reflected in Table III below.

\section{Financial}

Forty-five (7I.4\%) caregivers did not experience any work-related adjustments. Many indicated financial strain on a regular basis $(n=23 ; 36.5 \%)$ or at times $(n=17 ; 27 \%)$.

\section{Physical}

Forty-four (69.8\%) caregivers did not experience any sleep disturbances and 45 (7I.4\%) caregivers did not feel that caregiving was a physical strain.

\section{Psychological}

Most caregivers indicated that emotional adjustments were required on a regular basis $(n=37 ; 58.7 \%)$ or at times $(n=15 ; 23.8 \%)$. Forty $(63.5 \%)$ caregivers did not find patients' behaviour to be upsetting, although most of them felt upset that the person had changed so much from his/her former self, on a regular basis $(n=14 ; 22.2 \%)$ or at times $(n=26 ; 41.3 \%)$. Most caregivers $(n=36 ; 57.1 \%)$ did not report feeling completely overwhelmed at two months postdischarge.

\section{Social}

Caregivers experienced caregiving to be confining on a regular basis $(n=17 ; 27.0 \%)$ or at times $(n=20 ; 31.8 \%)$, while $34(54.0 \%)$ did not experience family adjustments.

\section{Personal}

Thirty-five $(55.6 \%)$ caregivers did not feel that caregiving was inconvenient and $34(54.0 \%)$ did not experience any changes in personal plans. However, other caregivers felt that there had been other demands on their time on a regular basis $(n=17 ; 27 \%)$ or at times $(n=27 ; 42.9 \%)$.

\section{Comparison of the FIM and MCSI scores}

The MCSI scores obtained from the caregivers were compared with the patients' FIM scores upon discharge. It was found that the patients of the $12(19.1 \%)$ caregivers who experienced a high burden of care (MCSI score $\geq 14$ ) had a median FIM score of 7I, indicating that the patients mostly needed moderate assistance upon discharge (FIM level 3). The $5 \mathrm{I}(8 \mathrm{I} .0 \%$ ) caregivers who experienced a lower burden of care (MCSI score < I4) had patients with a median FIM score of 90 , indicating that the patients mostly needed supervision/setup only upon discharge (FIM level 5). A statistically significant difference was found between the patients' FIM scores upon discharge and the burden of care experienced by their caregivers $(p=0.0040)$. Based on the MCSI and FIM scores, it was found that the higher the caregivers' burden of care, the lower the patients' level of independence, and vice versa.

\section{DISCUSSION}

\section{Demographic information}

Patients' and caregivers' demographic information correlates with literature stating that survivors of CVA mostly seem to be adults over 45 years of age ${ }^{53}$, although the median age in literature is slightly older for patients (67 years versus 58 years in this study)

Table III: Caregivers' $(n=63)$ responses provided on the Modified Caregiver Strain Index (MCSI)

\begin{tabular}{|c|c|c|c|}
\hline \multirow{2}{*}{ Item } & Yes, on a regular basis & Yes, sometimes & No \\
\hline & n (\%) & n (\%) & n (\%) \\
\hline My sleep is disturbed. & $10(15.9)$ & $9(14.3)$ & $44(69.8)$ \\
\hline Caregiving is inconvenient. & $7(11.1)$ & $21(33.3)$ & $35(55.6)$ \\
\hline Caregiving is a physical strain. & $9(14.3)$ & $9(14.3)$ & $45(7 I .4)$ \\
\hline Caregiving is confining. & $17(27.0)$ & $20(31.8)$ & $26(4 I .3)$ \\
\hline There have been family adjustments. & $14(22.2)$ & $15(23.8)$ & $34(54.0)$ \\
\hline There have been changes in personal plans. & $10(15.9)$ & $19(30.2)$ & $34(54.0)$ \\
\hline There have been other demands on my time. & $17(27.0)$ & $27(42.9)$ & $19(30.2)$ \\
\hline There have been emotional adjustments. & $37(58.7)$ & $15(23.8)$ & II (I7.5) \\
\hline Some behaviour is upsetting. & $10(15.9)$ & $13(20.6)$ & $40(63.5)$ \\
\hline $\begin{array}{l}\text { It is upsetting to find the person I care for has changed so much from his/her } \\
\text { former self. }\end{array}$ & $14(22.2)$ & $26(4 \mid .3)$ & $23(36.5)$ \\
\hline There have been work adjustments. & $7(11.1)$ & II (I7.5) & $45(7 I .4)$ \\
\hline Caregiving is a financial strain. & $23(36.5)$ & $17(27.0)$ & $23(36.5)$ \\
\hline I feel completely overwhelmed. & $8(12.7)$ & $19(30.2)$ & $36(57.1)$ \\
\hline
\end{tabular}


and younger for caregivers ( 45.6 years versus 52 years in this study ${ }^{22}$. Women seem to be more affected by $\mathrm{CVAs}^{54}$, which was also observed in this study.

\section{Patients' functional level upon discharge and two months post-discharge}

The FIM considers aspects only up to a residential integration level, and not at community integration or productive activity levels ${ }^{12}$. Nevertheless, it is still commonly used to evaluate patients' functional levels during rehabilitation and predict their functional prognosis after discharge ${ }^{37}$. According to the patients' FIM scores in this study, they required minimal assistance upon discharge; which may in part explain the median MCSI score which indicates caregivers experienced a minimal to moderate burden of care. This finding was to be expected, given the fact that all patients received comprehensive rehabilitation at a private inpatient rehabilitation unit, with the goal of assisting patients with individualised therapeutic programmes to become as functional and independent as possible ${ }^{10}$. Another South African study" also found that most patients were independent in activities of daily living or only needed minimal assistance after discharge from an inpatient rehabilitation unit. However, that study was not conducted at a rehabilitation unit with a programme similar to the one in this study, as described in the introduction.

Most caregivers felt that patients' abilities had improved since discharge, despite the fact that most patients did not receive outpatient therapy after discharge. This observation might indicate the value of returning to a familiar environment and being surrounded by loved ones and a support system. It also reflects the long time frame in which patients can still show improvement after suffering a CVA. Although most improvement takes place within the first four weeks following a CVA, continuous improvement can still be seen at three months and even at six months post-CVA ${ }^{55}$. Caregivers are already identified prior to a patient's discharge, which can also have a positive effect on his/her progress. Early identification of a caregiver in the inpatient rehabilitation process has been described as a factor contributing to recovery or improvement in functional outcomes ${ }^{29}$.

\section{Therapy received}

No patients in this study were completely independent (see Table II), and we therefore assume that they could still benefit from outpatient therapy after discharge from hospital. However, few patients continued with outpatient therapy, which correlates with literature stating that not many patients continue with outpatient therapy after discharge from hospitals ${ }^{2}$. Various contributing factors have been described, such as limited insight from caregivers and patients and differences in expectations, for example, patients feeling that therapy does not address all of their concerns or having different goals than therapist ${ }^{56}$. Other factors relate to health systems, such as a shortage of healthcare workers, challenges with finances and transport, and a lack of communication upon discharge ${ }^{2}$. In their strategic plan for the Prevention and Control of Non-Communicable Diseases 2013-17, the Department of Health identified "improved access to rehabilitative services, particularly at the community level" as a priority ${ }^{9}$. However, our participants reported a lack of access to outpatient therapy facilities and limited availability of these services, which further contributes to caregivers' burden of care.

\section{Home environment of patients}

Many patients were still reported to use assistive devices and caregivers also reported that house modifications may be necessary or helpful. However, as reported in the paragraphs above, minimal outpatient therapy and support for caregivers are available and this may contribute to caregivers' burden of care.

Participating patients came from provinces across the country, which highlights the need for more private inpatient rehabilitation units in order to prevent and address caregivers' burden of care post discharge. The unit where the study was conducted, has been described as the only accredited, dedicated acute physical rehabilitation unit in central South Africa ${ }^{10}$ (ISO 900 I:2008 accreditation).

\section{Caregiving as occupation}

The fact that most caregivers attended caregiver training at the rehabilitation unit possibly contributed to the relatively low burden of care experienced by caregivers in this sample. Caregiver training has been described as preparing caregivers for their new role and assisting with the patient's transition between inpatient rehabilitation and community integration after discharge ${ }^{57,58,59}$.

Caregivers appeared to have unbalanced occupational profiles ${ }^{59}$, as more than half of them did not have full-time jobs, only some of them spend more than four hours a day on recreational activities, and some of them spend more than four hours a day on household tasks. Should caregivers spend all of their time on caregiver-related duties and neglect other occupations such as sleep, leisure and social participation, it could affect their health and well-being. However, in this study, the estimated time spent on caregiving per day was not necessarily consistent with the expected hours as described in the literature ${ }^{33}$, as seen in Table II. Estimations done by the caregivers were subjective and the accuracy of their calculations was not verified. Thirty five $(55.6 \%)$ caregivers spend between two to four hours on caregiving per day (although they reported staying with the patient for at least four hours during the day) and 15 (23.8\%) caregivers indicated that they spend five to six hours on caregiving per day, which indicates far more hours of care than expected according to the FIM rating levels as distributed in Table $/ /^{33}$.

\section{Caregiver strain (burden of care) and associated factors}

Most of the caregivers experienced a minimal to moderate burden of care. This finding was contrary to another study that used the CSI and reported that $56 \%$ of CVA caregivers experienced a high burden of care after patients' discharge from an inpatient rehabilitation unit ${ }^{\prime \prime}$. However, the rehabilitation unit in that study was not in the private sector, and further research is needed to determine if the burden of care is lower for caregivers of patients with CVAs discharged from other private inpatient rehabilitation units, in order to support findings of this study, as the therapeutic service programme and resources in private sectors differ from that of governmental institutions.

The association between patients' FIM scores and their caregivers' MCSI scores is supported by previously published research that compared the hours of assistance needed from caregivers on a daily basis in relation to patients' FIM scores. The hours of assistance needed from caregivers decrease (along with their burden of care) as the patients' FIM scores, along with their functional levels, increase (see Table II on page 27) ${ }^{33}$. The median FIM scores in this study indicated that patients only needed minimal assistance upon discharge, which correlated with the median MCSI score, which reflected that caregivers experienced a minimal to moderate burden of care.

The authors acknowledge that burden of care experienced by caregivers is not necessarily related to the patient's physical function, and caregivers of patients with more cognitive than physical impairments also experience strain. This is supported by literature stating that cognitive abilities have a palpable influence on patients' abilities to optimally participate in activities of daily living, such as social activities, managing children, returning to work, or shopping for groceries, even when limited physical impairments are present ${ }^{\prime}$. The magnitude of cognitive impairments is not always obvious, which places a high burden on caregivers to take care of such patients'. It has been found in other studies that patients' cognitive abilities are also a predictor of caregivers' burden of care ${ }^{60}$.

\section{LIMITATIONS}

The answers to questionnaire items provided by the caregivers were subjective and a reflection of their perceived burden of care only, which could be regarded as a limitation to the study. Care- 
givers had difficulty giving estimations of hours spent on each of their responsibilities, which complicated the attempt to determine their occupational profiles, roles and occupations. The authors only aimed to give a description of their current occupational profiles.

Results may have been influenced by caregivers' different circumstances, in terms of whether they had assistance in their caregiving tasks. Caregivers reporting that they had between one and three persons assisting them with caregiver-related tasks could have had a positive influence on the burden of care experienced, as caregiver-related tasks could be shared. Some caregivers indicated that the patient's medical scheme provided a professional caregiver for two weeks after discharge, after which the primary caregiver had to take over, as is the case with patients subscribed to a specific option from one of the medical schemes ${ }^{30}$. Professional caregivers may have assisted with the transition between discharge from the inpatient rehabilitation unit and the home environment.

The study sample was fairly small and not representative of the whole population of patients with CVA or their caregivers, but only of patients and their caregivers discharged from the private inpatient rehabilitation unit where this study was conducted. The researchers also did not investigate if the caregivers had health problems that could have contributed to their burden of care.

\section{RECOMMENDATIONS}

Our results once again highlight that the transition between inpatient rehabilitation and discharge of the patient with CVA is generally not smooth, creating a situation where the patient may not reach optimal functionality and the caregiver experiences strain. This matter should receive attention on a macro level of healthcare provision. On a more clinical level, occupational therapists should work towards intervention methods attempting to support both the patient and caregiver post-discharge. These can include strategies such as initiating caregiver training from an earlier stage during the rehabilitation process and involving caregivers in the therapy process; adapting caregiver training programmes in order to better equip caregivers for their new roles; and appealing to medical schemes to cover outpatient therapy. The factors identified in this study to contribute to burden of care (social, financial and psychological adjustments, as well as occupational imbalance) should be considered whenever therapists are dealing with caregivers.

Further research is recommended to determine the procedures applied by other rehabilitation units for transition from inpatient to community reintegration.

\section{CONCLUSION}

This study investigated the burden of care experienced by caregivers of patients with CVA with functional impairment postdischarge. The functional impairments suffered by these patients often require full-time caregiver assistance and may become an extension of rehabilitation. The role of caregiving is often unplanned and can place a high burden of care on caregivers. However, it was found in this study that after completing a comprehensive private inpatient rehabilitation programme, patients generally needed minimal assistance with activities of daily living upon discharge, and that caregivers experienced minimal to moderate strain at two months post-discharge. Private inpatient rehabilitation can play a crucial role in reducing caregivers' burden of care, but the transition between private inpatient rehabilitation and full community integration remains an area that requires improvement in South Africa.

\section{ACKNOWLEDGEMENTS}

The researchers want to acknowledge all patients and their caregivers that participated in this study, the private inpatient rehabilitation unit for their approval and support throughout the study, and Dr. Daleen Struwig, medical writer/editor, Faculty of Health Sciences, University of the Free State, for technical and editorial preparation of the manuscript.

\section{REFERENCES}

I. Cawood J, Visagie S, Mji G. Impact of post-stroke impairments on activities and participation as experienced by stroke survivors in a Western Cape setting. S Afr J Occup Ther. 2016; 46: 10-I5. http://dx.doi.org/10.17159/2310-3833/2016/v46n2a3.

2. Mudzi W, Stewart A, Musenge E. Effect of carer education on functional abilities of patients with stroke. Int J Ther Rehabil. 2012; 19: 380-385. https://doi.org/10.12968/ijtr.2012.19.7.380.

3. Bertram MY, Katzenellenbogen J, Vos T, Bradshaw D, Hofman KJ. The disability adjusted life years due to stroke in South Africa in 2008. Int J Stroke. 20 I 3; 8: 76-80. http://dx.doi.org/ I0. I I I I/j. I 747-4949.2012.00955.x.

4. Mudzi W. Impact of caregiver education on stroke survivors and their caregivers. PhD thesis. Johannesburg: University of Witwatersrand; 2010.

mobile.wiredspace.wits.ac.za/handle/I0539/874I (accessed 24 January 2019).

5. Cawood J, Phil M, Visagie S. Stroke management and functional outcomes of stroke survivors in an urban Western Cape Province setting. S Afr J Occup Ther. 2016; 46: $21-26$. http://dx.doi.org/10.17/59/2310-3833/2016/v46n3a5.

6. Occupational Therapy Association of South Africa. Position statement on rehabilitation. S Afr J Occup Ther. 2017; 47: 63-64. http://dx.doi.org/10.17159/23 I0-3833/2017/v47n3al0.

7. Council for Medical Schemes. CMScript complete. 2015 collection. http://www.medicalschemes.com/files/CMScript/CMScriptComplete2015.pdf (24 January 2019).

8. Burns L. Acute neurorehabilitation - an introduction. Cont Med Educ. 2008; 26: 84-92.

www.cmej.org.za/index.php/cmej/article/view/553/0 (accessed 6 February 2019).

9. Human Science Research Council. Strategic plan for the prevention and control of non-communicable diseases 2013-17. https://extranet.who.int/ncdccs/Data/ZAF_B3_NCDs_STRAT_ PLAN_I_29_I_3[2].pdf. (accessed 24 January 20̄19).

10. Life Healthcare. Life Pasteur Hospital. https://www.lifehealthcare.co.za/hospitals/free-state/bloemfontein/ life-pasteur-hospital/. (24 January 2019).

II. Rouillard S, De Weerdt W, De Wit L, Jelsma J. Functioning at 6 months post stroke following discharge from inpatient rehabilitation. S Afr Med J. 2012; 102: 545-548. http://dx.doi.org//0.7196/SAMJ.5488.

12. Hassan S, Visagie S, Mji GM. The achievement of community integration and productive activity outcomes by CVA survivors in the Western Cape Metro Health District. S Afr J Occup Ther. 2012; 42: I I-24. http://www.sajot.co.za/index.php/sajot/article/view/I23 (accessed 6 February 2019).

13. Life Pasteur Hospital. Guidelines: Therapy staff orientation, Bloemfontein, 2013

https://www.lifehealthcare.co.za/hospitals/free-state/bloemfontein/ life-pasteur-hospital/.

14. Mudzi W, Stewart A, Musenge E, Africa S, Division E. Community participation of patients 12 months post-stroke in Johannesburg, South Africa. Afr J Prim Health Care Fam Med. 2013; 5: a426. dx.doi.org/10.4102/phcfm.v5il.426.

I5. Hasselkus BR, Murray BJ. Everyday occupation, well-being, and identity: the experience of caregivers in families with dementia. Am J Occup Ther. 2007; 61: 9-20. http://dx.doi.org/10.5014/ajot.6I.I.9.

16. Pierce $D$. Co-occupation: the challenges of defining concepts original to occupational science. J Occup Sci. 2009; 16: 203-207. http://dx.doi.org/10.1080/1442759I.2009.9686663.

I7. Pickens ND, Pizur-Barnekow K. Co-occupation: extending the dialogue. J Occup Sci. 2009; I6: I 5 I- I56. https://doi.org//0.1080/|442759|.2009.9686656.

18. Dalvand H, Hosseini SA, Rassafiani M, Samadi SA, Khankeh HR, Kelly G. Co-occupations: the caregiving challenges of mothers of children with cerebral palsy. Br J Occup Ther. 20I5; 78: 450-459. http://dx.doi.org/I0.I I 77/03080226|4562793.

19. Mahoney W, Roberts E. Co-occupation in a day program for adults with developmental disabilities. J Occup Sci. 2009; 16: 170-179. http://dx.doi.org/10.1080/14427591.2009.9686659.

20. Doidge K. Co-occupation categories tested in the mothering 
context. Dunedin, New Zealand: Otago Polytechnic; 2012. opres. op.ac.nz/bitstream/handle/.../OCC_Doidge_\%20Thesis\%20 \%282012\%29.pdf? (accessed 24 January 2019).

21. Ramugondo EL, Kronenberg F. Explaining collective occupations from a human relations perspective: bridging the individual-collective dichotomy. J Occup Sci. 2017; 22: 3-16.

https://www.tandfonline.com/doi/abs/10.1080/|4427591.2013.78 1920 (accessed 6 February 2019).

22. Bhattacharjee M, Vairale J, Gawali K, Dalal PM. Factors affecting burden on caregivers of stroke survivors: population-based study in Mumbai (India). Ann Indian Acad Neurol. 2012; I5: I I3- I 19. http://doi.org/l0.4103/0972-2327.94994.

23. Hilton J, Mudzi W, Ntsiea V, Olorunju S. Caregiver strain and quality of life 6-36 months post stroke. S Afr J Physiother. 201 3: 69: a382. http://dx.doi.org/10.4102/sajp.v69i4.382.

24. Morais HC, Soares AM, Oliveira AR, Carvalho CM, da Silva MJ, De Araujo TL. Burden and modifications in life from the perspective of caregivers for patients after stroke. Rev Lat Am Enfermagem. 2012; 20: 944-953. http://dx.doi.org/ I0.I590/S0 I04- I I6920I 2000500017.

25. Posner $\mathrm{G}$. The experience of employed caregivers, working in private South African homes, with patients who have suffered from a stroke. Master of Arts dissertation (Speech Pathology). Johannesburg: University of the Witwatersrand; 2015.

wiredspace.wits.ac.za/handle/ I0539/I 9598 (accessed 24 January 20 I9).

26. Kniepmann K. Female family carers for survivors of stroke: occupational loss and quality of life. Br J Occup Ther. 2012; 75: 208-2I6. http://dx.doi.org//0.4276/0308022 I2X|336/458480207.

27. McDougall C, Buchanan A, Peterson S. Understanding primary carers' occupational adaptation and engagement. Aust Occup Ther J. 2014; 6I: 83-9I. http://dx.doi.org/ I0.। I I I/I440-1630.12076.

28. Sedrez Celich KL, Maschio G, da Silva Filho CC, Gaffuri da Silva T, Silva de Souza S. Influence of family support in burden of caregivers of individuals with cerebrovascular accident sequelae. Invest Educ Enferm. 2016; 34: 544-550.

https://www.ncbi.nlm.nih.gov/pubmed/29737728 (accessed 6 February 2019).

29. Thomas M, Greenop K. Caregiver experiences and perceptions of stroke. Health SA Gesondheid. 2008; I3: a255. https://doi.org/10.4102/hsag.v1 3il.255.

30. Karahan AY, Kucuksen S, Yilmaz H, Salli A, Gungor T, Sahin M. Effects of rehabilitation services on anxiety, depression, care-giving burden and perceived social support of stroke caregivers. Acta Medica (Hradec Kralove). 2014; 57: 68-72.

citeseerx.ist.psu.edu/viewdoc/download?doi $=10.1$. I.870.973\&rep $=$ rep I ...pdf (accessed 6 February 2019).

31. Van Rooyen A. Case manager of the care coordination program for Discovery Health Insurance. Personal interview. I3 March 2018.

32. Joubert G, Bam R.H, Cronjé H.S. How to write a protocol: A manual for beginner researchers. Depatment of Biostatistics and Deaprtment of Obstetrics and Gynecology, University of The Free State. 2008.

33. Uniform Data System for Medical Rehabilitation. The FIM ${ }^{\circledR}$ instrument: its background, structure, and usefulness. Buffalo: UDSMR; 2012. https://www.udsmr.org/Documents/The Fim Instrument Background_Structure_usefulnwss.pdf. (accessed $2 \overline{4}$ January 2019).

34. Onega LL. The Modified Caregiver Strain Index (MCSI). The Hartford Institute for Geriatric Nursing, New York University Rory Meyers College of Nursing. Issue 14, revised 2018.

https://consultgeri.org/try-this/general-assessment/issue- 14.pdf. (accessed 24 January 2019).

35. Shirley Ryan Abilitylab. Rehabilitation Institute of Chicago. Rehabilitation measures database 2010. FIM_INstrument_Background_Structure_Usefulness.pdfary (accessed 24 January 2019).

36. Chumney D, Nollinger K, Shesko K, Skop K, Spencer M, Newton RA. Ability of Functional Independence Measure to accurately predict functional outcome of stroke-specific population: systematic review. J Rehabil Res Dev. 20 10; 47: 17-29. http://doi.org/10.1682/JRRD.2009.08.0140.

37. Carod-Artal FJ, Ferreira Coral L, Trizotto DS, Menezes Moreira C. Burden and perceived health status among caregivers of stroke patients. Cerebrovasc Dis. 2009; 28: 472-480. http://doi.org/10.I I59/000236525.
38. Pellerin C, Rochette A, Racine E. Social participation of relatives post-stroke: the role of rehabilitation and related ethical issues. Disabil Rehabil. 20I I; 33: 1055-1064.

http://dx.doi.org/I0.3109/09638288.2010.524272

39. Flynn RW, MacWalter RS, Doney AS. The cost of cerebral ischaemia. Neuropharmacology. 2008; 55: 250-256. http://doi.org/10.1016/j.neuro-pharm.2008.05.031.

40. Camak DJ. Addressing the burden of stroke caregivers: a literature review. J Clin Nurs. 20I5; 24: 2376-2382. https://doi.org/I0. I I I I/jocn. I 2884

4I. Ilse IB, Feys H, De Wit L, Putman K, De Weerdt W. Stroke caregivers' strain: prevalence and determinants in the first six months after stroke. Disabil Rehabil. 2008; 30: 523-530. https://doi.org//0.1080/09638280701355645

42. Chen MC, Chen KM, Chu TP. Caregiver burden, health status, and learned resourcefulness of older caregivers. West J Nurs Res. 20 I5; 37: 767-780. http://dx.doi.org/10.| I77/01939459|4525280.

43. Ekstam L, Johansson U, Guidetti S, Eriksson G, Ytterberg C. The combined perceptions of people with stroke and their carers regarding rehabilitation needs I year after stroke: a mixed methods study. Br Med J Open. 2015; 5: e006784. http://dx.doi.org/10.I I36/bmjopen-2014-006784.

44. Rigby H, Gubitz G, Eskes G, Reidy Y, Christian C, Grover V, Phillips S. Caring for stroke survivors: baseline and I-year determinants of caregiver burden. Int J Stroke. 2009; 4: 152- 158. http://dx.doi.org/ I 0. I | | |/j. I 747-4949.2009.00287.x.

45. Kamel AA, Bond AE, Froelicher ES. Depression and caregiver burden experienced by caregivers of Jordanian patients with stroke. Int J Nurs Pract. 2012; 18: 147-154. http://dx.doi.org/I0. I I I I/j. I440-I72X.20 I2.020 I I.x.

46. Mukherjee D, Patil CG. Epidemiology and the global burden of stroke. World Neurosurg. 20I I; 76(6 Suppl): S85-S90. http://dx.doi.org/10.1016/j.wneu.201 I.07.023.

47. Robinson B. Validation of a Caregiver Strain Index. J Gerontol. I983; 38: 344-348.

http://dx.doi.org/10.1093/geronj/38.3.344.

48. Hassan S, Visagie S, Mji G. Strain experienced by caregivers of stroke survivors in the Western Cape. S Afr J Physiother. 201 I; 67: 4-8. http://dx.doi.org//0.4102/sajp.v67i2.39.

49. Wasserman S, De Villiers L, Bryer A. Community-based care of stroke patients in a rural African setting. S Afr Med J. 2009; 99 : 579-583.

www.samj.org.za/index.php/samj/article/view/3284. (accessed 6 February 2019).

50. Life Healthcare. Integrated report 2018. https://www.lifehealthcare.co.za/media/2754/life-healthcareir-2018.pdf. (accessed 24 January 2019).

5I. Thornton M, Travis SS. Analysis of the reliability of the modified caregiver strain index. J Gerontol B Psychol Sci Soc Sci. 2003; 58: SI27-SI 32.

http://dx.doi.org/10.1093/geronb/58.2.SI27.

52. Douglas G. Altman-Practical Statistics for Medical Research. CRC Press Boca Raton, 1991.

53. Abboud H, Labreuche J, Arauz A, Bryer A, Lavados PG, Massaro A, Munoz Collazos M, Steg PG, Yamout BI, Vicaut E, Amarenco P. Demographics, socio-economic characteristics, and risk factor prevalence in patients with non-cardioembolic ischaemic stroke in low- and middle-income countries: the OPTIC registry. Int J Stroke. 2013; 8(Suppl AI00): 4-I3. http://dx.doi.org/I0.1 I I I/j. I747-4949.2012.00893.x.

54. Mamabolo MV, Mudzi W, Stewart AS, Olorunju S, Singh A. A study to determine post discharge functional improvements in patients with stroke. S Afr J Occup Ther. 2009; 39: 15-18. www.scielo.org.za/pdf/sajot/v39n l/05.pdf (accessed 6 February 2019).

55. Lee KB, Lim SH, Kim KH, Kim KJ, Kim YR, Chang WN, Yeom JW, Kim YD, Hwang BY. Six-month functional recovery of stroke patients: a multi-time-point study. Int J Rehabil Res. 2015; 38: 173-I80. http://dx.doi.org/l 0.1097/MRR.0000000000000108.

56. Koh W, Barr C, George S. Factors influencing post-stroke rehabilitation participant after discharge from hospital. Int J Ther Rehabil. 20I4; 2 I: 260-267. http://doi.org/10.12968/ijtr.2014.21.6.260. 
57. Perry L, Middleton S. An investigation of family carers' needs following stroke survivors' discharge from acute hospital care in Australia. Disabil Rehabil. 20II; 33: 1890-1900.

http://doi.org/I0.3109/09638288.20I I.553702.

58. Shyu YI, Chen MC, Chen ST, Wang HP, Shao JH. A family caregiveroriented discharge planning programme for older stroke patients and their family caregivers. J Clin Nurs. 2008; 17: 2497-2508. http://doi.org/I0. I I I I/j. I 365-2702.2008.02450.x.

59. Gustafsson L, Bootle K. Client and carer experience of transition home from inpatient stroke rehabilitation. Disabil Rehabil. 20I3; 35: $1380-1386$.

http://doi.org/I0.3109/09638288.2012.740I34.

60. Van Heugten C, Visser-Meily A, Post M, Lindeman E. Care for carers of stroke patients: evidence-based clinical practice guidelines. J Rehabil Med. 2006; 38: 153-158.

http://doi.org/I0.1080/I650I97050044I898.

\section{Corresponding Author}

\section{* Marieta Visser}

Email: vissermm@ufs.ac.za 